\title{
Better Drug Therapy for the Children of Africa: Current Impediments to Success and Potential Strategies for Improvement
}

\author{
Stuart M. MacLeod • Janet K. Finch • \\ William M. Macharia • Gabriel M. Anabwani
}

Published online: 12 April 2013

(c) Springer International Publishing Switzerland 2013

\begin{abstract}
A commentary is presented on the urgent need for a comprehensive effort to improve the practice of pediatric therapeutics in Africa. A call for action is addressed to a variety of practitioners internationally, many of whom possess skills that could be fruitfully applied to the improvement of health outcomes for African children. Successful engagement with the many challenges requires the complementary effort of researchers in basic and clinical pharmacology and toxicology, nurses, pharmacists, physicians, clinical pharmacologists, clinical pharmacists, and political leaders and civil servants. While a comprehensive or systematic review of the relevant literature has not been attempted, the authors have highlighted promising initiatives driven by international agencies and academic networks. Two African perspectives are presented to reinforce the prospect of child health gains that can be achieved through consistent pursuit of optimal therapy for conditions such as respiratory infection, diarrhea, malaria, and HIV/AIDS. There is an imperative for development of north-south and south-south partnerships that will amplify
\end{abstract}

\author{
S. M. MacLeod \\ University of British Columbia, Vancouver, BC, Canada \\ S. M. MacLeod ( $\square)$ \\ 950 West 28th Avenue, Vancouver, BC V5Z 4H4, Canada \\ e-mail: smacleod@cfri.ca \\ J. K. Finch \\ Child and Family Research Institute, Vancouver, BC, Canada \\ W. M. Macharia \\ Aga Khan University, Nairobi, Kenya \\ G. M. Anabwani \\ Botswana-Baylor Children's Clinical Centre of Excellence, \\ Gaborone, Botswana
}

current research efforts and mobilize existing knowledge concerning pediatric drugs. The overall goal is a multidisciplinary commitment to making essential medicines available at the right time, the right place, and in the right formulation for African children from infancy to adolescence.

\section{Introduction}

The challenge of delivering optimal drug therapy to children in Africa is undeniably complex and compounded by a shortage of both human and fiscal resources $[1,2]$. While much has been written about the worldwide failure of commitment over the past century to achieve evidencebased pediatric therapy [3, 4], in the 54 countries of Africa the situation is even more critical. African nations, along with some Asian counterparts, are subject to a disproportionate burden of childhood illnesses with related morbidity and mortality [5]. The African challenge is shown symbolically in Fig. 1, which presents a sample of six maps from those available on Worldmapper.org showing the maldistribution of illness burden and fiscal resources to support treatment [6].

In the past 20 years, international funders and agencies such as WHO, UNICEF, Save the Children, the Wellcome Trust, and the Clinton and Bill \& Melinda Gates Foundations, among others, have recognized the importance of improved nutrition and optimal drug therapy as the most cost-effective interventions capable of saving lives and reducing morbidity among newborns, infants and young children. An extremely important advance has been WHO's promulgation since 2005 of integrated management of childhood illness (IMCI) [7], with the objective of cutting across vertical disease-based approaches. Nonetheless, 


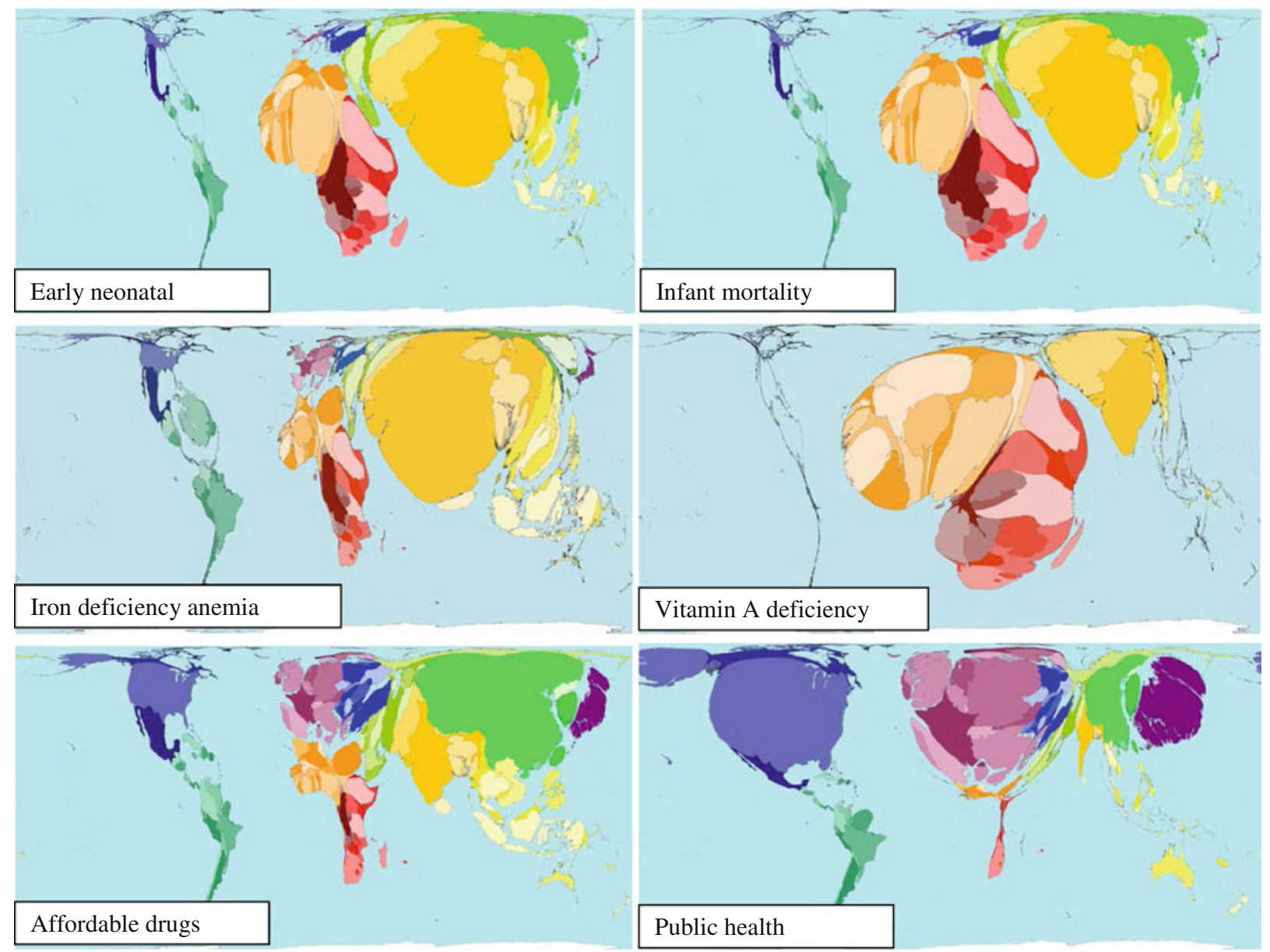

Worldmapper.org; (C) Copyright SASI Group (University of Sheffield) and Mark Newman (University of Michigan). Reprinted with permission.

African nations display disproportionately high rates of infant and neonatal mortality and are home to much of the world's vitamin A deficiency. Iron deficiency anemia is relatively common. Access to affordable drugs or public health services is suboptimal.

Fig. 1 Maldistribution of illness burden and fiscal resources to support treatment [6]

optimal treatment remains elusive in many parts of Africa for conditions such as neonatal sepsis, childhood respiratory infections, diarrhea, malaria, acute and chronic pain, and HIV/AIDS.

In 2007, the World Health Assembly (WHA) recognized the urgency of closing the gap in evidence supporting childhood prescribing and passed WHA resolution 60.20 calling for better medicines for children [8]. Since that time, an essential medicines list for children has been introduced and has gone through two revisions [9]. Another good start has been made in improving standardized treatment guidelines (STGs) for resource-poor settings through release of the Model Formulary for Children by the WHO [10]. Furthermore, an up-to-date revision of the well-travelled "pocket book" for acute care of children in resource-poor settings [11] is scheduled for release in 2013. Work that has been conducted under WHO's Better Medicines for
Children program, with sponsorship from the Bill \& Melinda Gates Foundation, includes an emphasis on the need for new formulations appropriate for use in remote areas which are at times subject to climate extremes $[12,13]$.

The paper that follows offers a perspective on the environment that is impeding achievement of better drug therapy for children in Africa. The report is not intended as a comprehensive review of African pediatric pharmacology research, but rather as an environmental scan that reinforces the need for international cross-disciplinary effort. Both global and regional strategies for improvement are discussed. The required mix of political leadership, altered human behavior, research development, innovative professional education in medicine, pharmacy and nursing, and improved clinical practice in therapeutics and toxicology will not be easily achieved without comprehensive focused effort from many quarters. 
The target audience for these remarks is a broad crosssection of clinicians, researchers, and health care decision makers who possess skills critical to the future improvement of therapeutic outcomes for African children.

\section{How Far Have We Come?}

The 2011 report, "Assessing Progress in Africa toward the Millennium Development Goals" [14, 15], describes mixed improvement in African nations across a variety of indicators. As things stand today, it appears certain that there has been insufficient headway to permit full achievement of the Millenium Development Goals (MDGs) as envisaged by 2015, and this was confirmed last year by the annual report of Countdown to 2015 [16] and in the analysis by Liu and colleagues [17]. In general, progress that has been made in African nations favors higher income groups and urban populations. Poorer, less educated, rural groups continue to be marginalized. Although all MDGs are interconnected, target $4 \mathrm{a}$, of reducing the mortality rate among children under 5 years of age by two-thirds between 1990 and 2015, remains particularly elusive. An overall $28 \%$ reduction has been achieved over a period of 20 years; however, the under-5 mortality rate remains high in the majority of African countries [18], with at least 22 still registering rates greater than 100 deaths per 100,000 live births in 2011 [19]. Where success has been achieved, the report suggests that the most influential positive influences are leadership commitment, strong partnerships, and enhanced service delivery programs. Ready access to essential medicines, appropriately used, is a critical condition for success. The report concludes that further progress must include greater availability of antibiotics for acute respiratory infections, oral rehydration salts for diarrhea, improved immunization, use of treated bednets, and access to appropriate antimalarial drugs. A refocusing, specifically on pneumonia and diarrhea, two of the three leading killers of young children in Africa, was urged.

The African Report on Child Well Being published by the African Child Policy Forum in 2011 explored the obligation of African societies to invest more heavily in their children [20]. It underscored the importance of the national budget as a key government policy document and advocates increased budgetary allocations to sectors that most impact children's lives. Policy decisions by government should be based on the principles of distributive justice, equity, provision for the needs of all, freedom from poverty and discrimination, social inclusion, and the development of human capabilities.

\section{Better Medicines for Children: Essential Elements}

In order for African nations to improve survival and lessen morbidity for children, it will be mandatory to promote better drug therapy. It is anticipated that required improvements will be pursued within the context of broad, established initiatives, including child survival strategies [21], the IMCI strategy [22], and the Millennium Development Goals [19, 20]. As described by the African Child Policy Forum, the foundational effort will be heightened investment in child-centered implementation strategies that incorporate strong governance, leadership, the correct number and skill mix of human resources, and improved data and information management systems [20].

To avoid confusion, it will also be important in many situations to carefully define the age range encompassed by terms such as 'pediatric' or 'child'. While the concerns of adolescents are undeniably important, for the purposes of this commentary it may be argued that the priority focus of African pharmacotherapy interest should be on newborns, infants, and prepubertal children.

\section{Requirements for a Robust Pediatric Pharmaceutical Policy Framework}

\subsection{Essential Medicines Lists for Children}

Initially, a review of the current national Essential Medicines List (EML) in African countries is required to determine whether the needs of children (neonates to puberty) have been considered. It is also necessary to perform a detailed assessment of burden of disease at the country or regional level, and to build on all readily available tools as listed in Table 1. Using such information, each country will be positioned to develop an EML for children (EMLc) that meets its own needs. It must be consistent with current evidence-based standard treatment guidelines and optimal procurement procedures. Ideally, each country's EMLc should be revised every 2 years; however, given the widespread shortage in African nations of highly qualified personnel with child health expertise in relevant disciplines, this goal is likely to prove challenging.

\subsection{Standard Treatment Guidelines}

All countries in Africa can build on more than 30 years of adult experience with essential medicines and the development of national treatment guidelines. STGs directly applicable to children will, however, be required if the leading causes of mortality are to be addressed in a regionspecific manner. STGs must be created or revised and linked to an EMLc that is relevant, applicable to the local/ regional setting, and compatible with available fiscal resources. Once this is achieved, the subsequent process is iterative and aimed at maintaining the guidelines and providing necessary communication and educational 
Table 1 Tools available to guide design of optimal programmes for pediatric drug therapy

- Millennium Development Goals

- WHO EMLc, 3rd edition

- WHO Model Formulary for Children

- WHO pocketbook of hospital care for children in resource poor settings

- Framework for integrated management of childhood illness (IMCI)

- Current textbooks of pediatric clinical pharmacology and therapeutics ${ }^{\mathrm{a}}$

- Other national formularies for treatment of children ${ }^{\mathrm{b}}$

EMLc Essential Medicines List for children

${ }^{a}$ For example, Yaffe and Aranda [90]

${ }^{\mathrm{b}}$ For example, British National Formulary for Children [91]

activities in order to promote adherence at every level of health care service and within the supply chain [23].

\subsection{Adequate Number and Mix of Human Resources}

Health manpower shortages in most African countries are the greatest single impediment to progress toward better medicines for children. There is a distinct shortage of physicians trained in clinical pharmacology and toxicology, clinical, hospital, and community pharmacists, pharmaceutical scientists, nurses, and relevant researchers with a critical role to play in promoting safe and effective drug therapy. Significant human resource limitations throughout Africa impede the successful development of EMLc/STGs and the knowledge transfer and mobilization activities required to assure widespread engagement with active interventions. Strategies to acquire dedicated fiscal resources to increase training opportunities for health care workers and community health volunteers across all relevant disciplines must be identified and implemented. Attention should also be paid to ensuring the appropriate mix and distribution of personnel alongside improved implementation of retention initiatives to minimize brain drain [24-29].

A parallel opportunity exists for thorough exploration of task-shifting innovations that have much to offer in Africa. The North American/European idealized model of the subspecialist clinician scientist is unlikely to be adopted quickly in Africa. Attention should be paid alternatively to the training and technical support of dedicated teams aligned with objectives of patient-centered care and improved clinical outcomes that may be achieved through extended application of strengthened STGs. Africa also needs a new clinical research model and provides an extraordinary opportunity for innovation that may achieve some of the outcomes that still remain an elusive target in more economically developed regions [30].

\subsection{Data Availability}

The best achievable baseline data for each African country, disaggregated by locality and region, will ultimately be required in order to identify the burden of illness for common childhood conditions and guide development of STGs. The enhanced use of modern wireless technology should facilitate the collection of relevant health data with significant impact on the ability to plan research studies and to prioritize clinical interventions. At a minimum, required data elements include those relevant to therapeutic research and shown in Table 2 [23].

\subsection{Relevant Clinical Research}

There is an enormous need for further development of clinical research capacity in Africa relevant to the needs of children. More clinical trials should be conducted in African settings, and work should continue as initiated by WHO on the development of a framework for support and management of such trials. The training of highly qualified personnel able to participate in clinical pediatric trials in low- and middle-income countries is a mandatory component of any such effort [31,32].

StaR Child Health, an important resource group supporting and advocating augmented clinical research capacity for children, has emerged in the last 5 years: "a group of methodologists, clinicians and policy makers who seek to enhance the quality, ethics and reliability of pediatric clinical research by promoting use of evidence-based standards or guidance for clinical studies with children." Beginning with an initial meeting in 2009, StaR Child Health has already focused on the needs of clinical trialists in low- and middle-income settings [31, 32], and this emphasis has been maintained through subsequent meetings in 2010 and 2012 [33] and by the publication of an initial set of six research standards in 2012 [34-39].

The key objectives described for StaR Child Health include the following [33]:

- raising awareness of the crucial importance of research design, conduct. and reporting of clinical research;

- assisting in the development, dissemination. and implementation of evidence-based standards for clinical research for children;

- becoming a global center providing resources and supporting training related to the design, conduct, and reporting of clinical research in children;

- conducting empirical research on design, conduct, and reporting of clinical research.

\subsection{Knowledge Transfer}

Knowledge transfer and mobilization activities are vital to the establishment of any program promising better 
Table 2 Data elements required as a foundation for African therapeutic choices

- Accurate demography and burden of illness measurements

- Data on current national expenditure for pediatric medicines

- Documentation of the availability of an essential pediatric drug basket on the shelf at various levels within the health system

- Documentation of supply bottlenecks and occurrence of stockouts

- Current prices of various formulations for children, including liquids and dispersibles

- Regional costs for transportation and storage of liquid preparations prepared at source

- Local and regional availability of pediatric dosage forms, supply source and utilization monitoring

- Accurately described local use patterns for extemporaneous preparations

- Aggregated, reliable data on adverse drug reactions, drug errors and drug interactions

- Defined extent and frequency of antibiotic resistance (local and regional)

medicines for African children. These activities include the creation and dissemination of up-to-date country-level EMLcs, and the provision of accurate information to patients and health workers at the point of care.

Individuals working in the fields of medicine, pharmacy, nursing, and allied health programs need up-to-date information regarding EMLcs and STGs at every level of training, from undergraduate through to specialization and continuing education. There is also a demand for education regarding the special needs of children directed to individuals, such as those on therapeutic drug committees, employed within the pharmaceutical industry and local manufacturers, and policy makers and administrators at all levels of the health care delivery system.

To achieve this goal, all educators must also have access to the most current and accurate information and tools. Novel and locally applicable knowledge translation and dissemination activities must be identified and put in place, in order to ensure that essential information reaches all the aforementioned in a timely and efficient manner, regardless of geographical, technological, and/or other barriers. Professional organizations can be pivotal in recognizing the importance of disseminating information pertaining to pediatric care, and could help in a significant way to advance these goals [40, 41].

\subsection{Regulation, Procurement, Adherence, and Quality Monitoring}

In order to make the best and most rational procurement decisions, a region-specific understanding of burden of disease and historical purchase and utilization profile is necessary. Purchasing processes can be supported by national pricing policies and guidelines, as well as through buying based on a tendering process and the purchasing of medications in bulk [42]. Although generic formulations are usually cheaper to acquire, the use of generics must be tempered by careful investigation of quality. The WHO prequalification process is seen as enhancing a rational procurement process, and consideration might be given to expanding its use [43]. The establishment of a global virtual warehouse of quality, sources, and prices of medicines for children would convey significant advantage in future.

Clearly, a significant opportunity exists for national regulatory authorities in high-income countries to play a critical supporting role if teamed with counterparts in Africa. The potential advantages of such partnerships have been under active discussion since 2008, with leadership from the International Conference of Drug Regulatory Authorities (ICDRA) and the network of regulatory authorities for pediatric medicines [44].

There are precedents for success to be seen in the work of the Pan American Health Organization in encouraging stronger regulators in Brazil and Mexico to seek synergies with other Latin American counterparts [45].

Technology is already providing innovative ways to monitor the quality of drugs. One such example is the use of a text-messaging verification system to address the identification of counterfeit pharmaceuticals in Africa which is now in use for a small number of drugs in selected countries [46].

Efforts to engage children and their families in decision making about treatment is vitally important to encouragement of adherence with therapeutic regimens and achievement of better outcomes. New approaches such as regular cellphone communication may contribute greatly to improved adherence, even in jurisdictions with low health literacy [47].

\section{Back to Reality}

The literature is replete with descriptions of the challenges faced by those who wish to improve therapeutic outcomes for mothers, newborns, infants, and children. For illustration, two African perspectives are presented here. One describes efforts to better manage the control and treatment of diarrhea, pneumonia, and malaria. The second is a success story from Botswana showing the remarkable progress made in the prevention and treatment of childhood HIV/AIDS. Both examples serve to demonstrate the potential gains in child health from optimal clinical use of drugs and vaccines. 


\subsection{A Perspective on Major Infectious Causes of Mortality}

Diarrheal diseases, pneumonia, malaria, and HIV continue to be responsible for most deaths among children under 5 years of age in sub-Saharan Africa, despite acceleration of efforts for their containment through pursuit of relevant Millennium Development Goals [14, 15]. Although outcome statistics are changing rapidly with trends to improved survival, there were still 7.6 million deaths reported in 2010 [17] and 7.2 million deaths in 2011 among children under 5 years of age [19]. The major causes of mortality beyond the neonatal period in children under 5 years of age remain pneumonia (14.1\%), diarrhea (9.9\%), and malaria $(7.4 \%)$, and this pattern appears to hold in Africa as in other developing regions [19].

In absolute numbers, the greatest success in mortality reduction in Africa has been seen in Ethiopia, Liberia, Madagascar, Malawi, and Niger [48]. A common denominator for good performance in these countries has been a concerted public health approach that incorporates nutrition, immunizations, breastfeeding, vitamin A supplementation, and safe water access. Nonetheless, uptake of low cost interventions for pneumonia, diarrhea, and malaria, which together are responsible for about one-third of deaths in children under 5 years of age, has remained unacceptably low [49].

Dramatic reductions in diarrhea have been achieved in recent years. Simple measures such as hand-washing alone have been shown to reduce diarrhea episodes by up to $30 \%$ [50]. Although coverage with rotavirus vaccination in low-income countries remains low, its effectiveness in reducing the incidence and adverse impacts of the most common cause of infective diarrhea has been established [51]. Safer and more effective low osmolarity oral rehydration solutions are also now available for use at home and in health facilities [52].

A recent double-blind, randomized, placebo-controlled trial has confirmed the utility of zinc as an adjunct treatment of young infants with probable severe bacterial infections [53]. Zinc supplementation could have additional benefits in reducing duration and severity of diarrhea [54, 55]. Although there is no evidence to suggest that addition of vitamin A and zinc to acute pneumonia treatment improves outcome, [56, 57] zinc supplementation has proven preventive effects and is associated with lower incidence and prevalence of pneumonia $[56,57]$. Hence, increased efforts are indicated to improve zinc access and use in developing countries [58]. Also, considering the high prevalence of HIV infection in sub-Saharan Africa, and that vitamin A has been shown to reduce diarrhea in children with HIV infection or exposure, its widespread use should be advocated as an extra tool for containing childhood illness burden in the region $[59,60]$.
Probiotics might also contribute to shortened duration and severity of diarrhea, although more evidence should be sought before their widespread use can be recommended [61]. Alarmingly, demographic and health survey data collected between 1998 and 2003 and showing a decline in use of oral rehydration therapy by as much as $32 \%$ were reported in Nigeria and Kenya [62, 63]. This has been attributed to cultural beliefs and inconsistencies in health messages from healthcare providers.

In a systematic review, Christopher et al. [64] found promise in the practice of employing community health workers to attain more effective delivery of cures for malaria, pneumonia, and diarrhea in sub-Saharan Africa. In Tanzania, it was found that first-level health care workers were reluctant to accept IMCI guidelines, suggesting that re-training and closer monitoring are needed [65]. It has been shown that implementation of evidence-based treatment guidelines is effective in reducing antimicrobial resistance and hospital-acquired infections when used appropriately [66]. A survey on use of inpatient treatment guidelines for HIV in adults, malaria in children and adults, pre-eclampsia, diarrhea in children, and hypertension in the Southern Africa Development Community (SADC) identified substantial gaps in quality of evidence in available guidelines and the extent to which they were implemented [67]. These findings are consistent with the reality that most health facilities in Africa have not yet adopted standard treatment guidelines and, even where they exist, adherence may prove to be very low. This is unfortunate, considering that oral amoxicillin, which can be administered at home, has been found to be as effective as parenteral penicillin in treatment of children with uncomplicated severe community-acquired pneumonia without hypoxia [68]. The systematic review by Christopher and colleagues concluded that improved availability of well-trained and motivated community health workers had the potential to reduce childhood mortality rate from malaria, pneumonia, and diarrhea in sub-Saharan Africa by 25-30 \% [64].

While many countries in Africa now have hemophilus influenzae type B (HIB) vaccine included in their routine national immunization schedules, rotavirus and pneumococcal vaccines have not yet gained widespread acceptance despite their demonstrated efficacy and potential for controlling childhood diarrhea and pneumonia in low-income countries.

\subsection{Impact of Antiretrovirals on Children in Botswana in Less than a Decade}

According to the 2002 UNAIDS update, more than 330,000 out of the total population of 1.5 million in Botswana had been infected with HIV, and there were 26,000 estimated deaths due to AIDS in 2001 alone. Statistics from 2002 
indicate that $38.8 \%$ of the economically productive and sexually active adults (aged 15-49 years) had HIV infection/AIDS [69]. In 1997, it was estimated that AIDS patients occupied $60 \%$ of hospital beds in medical wards. The large-scale effects of the AIDS epidemic in Botswana impacted virtually all aspects of society. According to estimations and projections by the US Bureau of the Census, the life expectancy in Botswana in 1996 was down from a projected 61 years in the absence of AIDS to 45 years as a result of the HIV/AIDS epidemic. Accordingly, by 2010, it was estimated that the life expectancy in Botswana would have declined further to 33 years [70]. Households faced large financial burdens due to loss of income support from family members who died of the disease, as well as increasing costs of treatment of HIV infection/AIDS and associated co-morbidities [71]. Children-being the most vulnerable in any community-were not spared.

Before 2001, there was little access to antiretroviral drugs (ARVs) in Botswana; $<1 \%$ of HIV-infected patients received limited subsidy for their ARV treatment via medical insurers [72]. Virtually no children were receiving ARVs. Although nearly all expectant women (>95\%) received antenatal care and delivered in hospitals or clinics with qualified birth attendants, and free services to prevent mother-to-child transmission of HIV (PMTCT) were introduced in 1999, uptake remained low until routine HIV testing "with opt-out" was introduced in 2004. In 2001, the government of Botswana committed to providing highly active antiretroviral therapy (HAART) to all qualifying citizens. Adult patients began to access HAART in public hospitals that year, while children followed in mid-2002.

The impact of HIV drugs and strong political will and commitment over the last decade has been incredible. According to the UNAIDS Botswana Country report (2010), $90 \%$ of all the estimated 19,000 HIV-infected children are receiving HAART, and the proportion of babies born to HIV-positive mothers who were infected decreased from $20.7 \%$ in 2003 to $3.8 \%$ in 2007. The mortality rate for children younger than 5 years in 1990 was 58 per 1,000 live births and worsening. Because of non-availability of ARVs, mortality in children under 5 years of age peaked at 124 per 1000 live births in 2006 and then dropped to 47.7 per 1000 live births by 2010-largely due to the impact of ARVs [73].

\section{Conclusions and Actions}

While these brief reports show the enormous potential for gain, there are many more examples of conditions associated with widespread morbidity and mortality where optimal therapy remains an elusive goal. For example, little is known about how best to manage the convergence of malnutrition, hypoxia, dehydration, and sepsis in young children. Even best practice for management of acute malaria among infants in remote settings remains controversial, although there is promise of increased survival with the early use of rectal artesunate as an interim measure [74, 75]. Progress continues to be made in the development of new antimalarial therapies [76, 77] and development of effective vaccines remains a goal that many still expect to achieve [78, 79].

Also deserving of attention by those pursuing better drug therapies for African children is the challenge of neglected tropical diseases. Hotez et al. [80, 81] has written compellingly about the need to bring research capacity to bear on conditions such as leishmaniasis, helminthic diseases, trypanosomiasis, schistosomiasis, and sickle cell anemia. While these conditions cause or contribute untold morbidity and mortality, they tend to be ignored by usual research sponsors, including both international agencies and the private sector.

There are, in addition, some very practical issues in pediatric therapeutics that are likely to gain deserved attention from the next generation of pediatric pharmacologists, including, for example, burn treatment, palliative care, management of childhood cancer, and development of new approaches to severe pain in chronic conditions such as cancer, sickle cell anemia, or major physical deformities [82, 83]. A comprehensive research strategy is urgently required.

As Voltaire observed, "best is the enemy of the good [84]." The challenges to achievement of optimal therapy for African children are numerous and daunting; however, there are grounds for cautious optimism. Lessons can be drawn from a number of positive initiatives, including the WHO Make Medicines Child Size program [85], the African Vaccine Regulatory Forum [86], the Pan African Clinical Trials Registry [87], and the European and Developing Countries Clinical Trials Partnership [88]. In parallel, a compelling argument has been made by Hill and her colleagues for adoption of a realistic focus on the inclusion of priority medicines in evidence-based national essential medicines lists [89]. Such developments point toward a better future featuring science-based evolution of African childhood therapeutics.

In conclusion, there is an immediate need for a concerted effort within Africa to advocate for better medicines for children. Although many organizations have shown an interest in this critical area, it is still important to identify a body willing to take responsibility for continent-wide leadership. In-country teams need to engage their Ministries of Health, who can then drive the process and in turn work with the National Drug Regulatory Authorities and local professional and academic leaders to support 
effective structures and processes within the procurement and supply chain systems. Key leaders from schools of pharmacy and medicine, along with practitioners in the fields of pharmacy, clinical pharmacology, and related health disciplines, as well as medical and pediatric professional associations, must all be actively engaged in this process. Other in-country and international stakeholders should also be enlisted to work towards better medicines for children.

Overall, the steps that need to be taken in Africa to improve medicinal therapy for children are known, and there are many individuals at the country level who are committed to working on initiatives that would help to make essential medicines available at the right time, the right place, and in the right formulation for children, from infancy to adolescence. The critical element now needed is the political will to identify the resources required to bring these improvements to fruition across the continent.

There is a need for new north-south and south-south partnerships that will extend current research efforts and mobilize existing knowledge in pediatric pharmacology and pharmacy. As part of that mobilization, it is essential to confront the significant shortfalls in numbers of qualified personnel able to address high priority problems or to pursue innovative task-shifting initiatives. Educational programs for health professionals, clinical researchers, child health workers, pharmacologists, and pharmacists should be urgently developed with an African perspective and the aim of increasing the human resource base available for the research and educational efforts required.

Not all low-income countries perform to the same level in pediatric therapeutics. Some countries have worked consciously to develop a more child-friendly system and have emphasized the development of appropriate treatment guidelines while improving access to essential medicines for children. Issues of procurement, distribution, and access to child-appropriate drug treatment have been addressed effectively in some, but not all, African countries. The conclusion that some African countries do more for children with the same or fewer resources than their peers is inescapable. The countries most successful in meeting the therapeutic needs of children are those that have the political will and have committed elected and professional leadership to serve this cause.

Acknowledgments The motivation for the preceding commentary came from participation in a series of international meetings centred on pediatric therapeutics and clinical trials. The first was convened by the World Health Organization in Accra, Ghana, in 2009. Many of the issues reviewed in this commentary first arose at that meeting. Further inputs have come from three meetings of StaR Child Health, Amsterdam 2009, Vancouver 2010, and Winnipeg 2012. In addition, two of the authors (S.M.M., G.A.) participated in a symposium addressing the challenges of conducting clinical trials in low- and middle-income countries held as a satellite to the 2010 meeting of the International Union of Basic and Clinical Pharmacology in Copenhagen. The report is not intended as a comprehensive review of African pediatric pharmacology research but rather as an environmental scan that reinforces the need for international cross-disciplinary effort. The opinions expressed are those of the authors and not of the international agencies and foundations cited.

Funding No sources of funding were used to assist in the preparation of this review.

Conflicts of interest The authors have no conflicts of interest that are directly relevant to the subject matter of this commentary.

\section{References}

1. Global Health Workforce Alliance. Global forums on human resources for health. Uganda 2008, Thailand 2011 (online). Available from URL: http://www.who.int/workforcealliance/ forum/en/index.html. Accessed 2013 Jan 2.

2. Molyneux E, Mathanga D, Witte D et al. Practical issues in relation to clinical trials in children in low-income countries: experience from the front line. Arch Dis Child. doi:10.1136/ archdischild-2011-301476.

3. MacLeod S. Developing better medicines for children: addressing international priorities. Am Pharm Rev. 2012;15:74-80.

4. MacLeod S. The plight of paediatric drug therapy. Paediatr Child Health. 2011;16:529-31.

5. UNICEF. State of the World's Children 2012: Children in an urban world (online). Available from URL: http://www.unicef. org/sowc2012/pdfs/SOWC\%202012-Main\%20Report_EN_13Mar 2012.pdf. Accessed 2013 Jan 2.

6. Worldmapper (online). Available from URL: http://www.world mapper.org. Accessed 2013 January 2.

7. World Health Organization Department of Child and Adolescent Health and Development. IMCI Integrated Management of Childhood Illness. 2005 (online). Available from URL: http:// whqlibdoc.who.int/publications/2005/9241546441.pdf.

8. WHO. 60th World Health Assembly Resolution. WHA 60.20: Better medicines for children. 23 May 2007 (online). Available from URL: http://www.who.int/gb/ebwha/pdf_files/WHA60/A60_ R20-en.pdf. Accessed 2013 Jan 2.

9. WHO. Model List of Essential Medicines for Children (online). Available from URL: http://www.who.int/childmedicines/publications/EMLc\%20[2].pdf. Accessed 2013 Jan 2.

10. WHO Model Formulary for Children 2010 (online). Available from URL: http://www.who.int/selection_medicines/list/WMFc_ 2010.pdf. Accessed 2013 Jan 2.

11. Pocket book of hospital care for children: guidelines for the management of common illnesses with limited resources. World Health Organization. 2005 (online). Available from URL: http:// www.who.int/maternal_child_adolescent/documents/9241546700/ en/index.html. Accessed 2013 Jan 2.

12. World Health Organization. Report of the informal expert meeting on dosage forms of medicines for children. Geneva, Switzerland. December 15-16, 2008 (online). Available from URL: http:// www.who.int/childmedicines/progress/Dosage_form_reportDEC 2008.pdf. Accessed 2013 Jan 2.

13. Consultative meeting of an informal working group on extemporaneous formulations of medicines for children. UNICEF Copenhagen. 20 July 2010 (online). Available from URL: http://www.who.int/ childmedicines/progress/UNICEF_formulations.pdf. Accessed 2013 Jan 2. 
14. Assessing progress in Africa toward the millennium development goals. MDG report 2011 (online). Available from URL: http:// www.who.int/childmedicines/progress/Dosage_form_reportDEC 2008.pdf. Accessed 2013 Jan 2.

15. United Nations Development Programme. The millennium development goals: Eight goals for 2015 (online). Available from URL: http://www.undp.org/mdg/basics.shtml. Accessed 2013 Jan 2.

16. Countdown to 2015. Building a future for women and children: The 2012 report (online). Available from http://www.countdown 2015mnch.org/reports-and-articles/2012-report. Accessed 2013 Jan 18.

17. Liu L, Johnson HL, Cousens S; for the Child Health Epidemiology Reference Group of WHO and UNICEF et al. Global, regional, and national causes of child mortality: an updated systematic analysis for 2010 with time trends since 2000. Lancet. 2012; 379: 2151-61.

18. UNICEF. State of world's children 2011. Under five mortality rankings 2009 (online). Available from URL: http://www. unicef.org/sowc2011/pdfs/UNDER-FIVE\%20MORTALITY\%20 RANKINGS_12082010.pdf. Accessed 2013 Jan 2.

19. Lozano R, Wang H, Foreman KJ, et al. Progress towards Millennium Development Goals 4 and 5 on maternal and child mortality: an updated systematic analysis. Lancet. 2011;378: 1139-65.

20. The African Child Policy Forum. The African Report on Child Wellbeing 2011. Budgeting for children (online). Available from URL: http://www.ancefa.org/IMG/pdf/African_Report_on_ Child_Wellbeing_2011.pdf. Accessed 2013 Jan 2.

21. UNICEF. The state of Africa's children 2008. Child survival (online). Available from URL: http://www.unicef.org/sowc08/ docs/SOAC_2008_EN_A4.pdf. Accessed 2013 Jan 2.

22. World Health Organization. Maternal, newborn, child and adolescent health. Documents on the integrated management of childhood illness [IMCI] (online). Available from URL: http://www.who.int/maternal_child_adolescent/documents/imci/ en/index.html. Accessed 2013 Jan 2.

23. World Health Organization. Workshop on Essential Medicines Lists and Better Medicines for Children. Meeting report. Accra, Ghana, 2-4 August 2009 (online). Available from URL: http:// www.who.int/childmedicines/progress/Accra_final.pdf. Accessed 2013 Jan 2.

24. Anywangwe SCE, Mtonga C. Inequities in the global health workforce: the greatest impediment to health in sub-Saharan Africa. Int J Environ Res Publ Health. 2007;4:93-100.

25. Chopra M, Munro S, Lavis JN, et al. Effects of policy options for human resources for health: An analysis of systematic reviews. Lancet. 2008;371:668-74.

26. Conway MD, Gupta S, Khajavi K. Addressing Africa's health workforce crisis. McKinsey Q. 2008;1:98-105.

27. McCoy D, Bennett S, Witter S, et al. Salaries and incomes of health workers in sub-Saharan Africa. Lancet. 2008;371:675-81.

28. Scheffler RM, Mahoney CB, Fulton BD, et al. Estimates of health care professional shortages in sub-Saharan Africa by 2015. Health Aff. 2009;28:w849-62.

29. International Pharmaceutical Federation. 2009 FIP Global Pharmacy: Workforce Report. The Hague (online). Available from URL: http://www.fip.org/files/fip/PharmacyEducation/FIP workforce_web.pdf?page=menu_resourcesforhealth. Accessed 2013 Jan 2

30. Gelijns AC, Gabriel SE. Looking beyond translation-integrating clinical research with medical practice. New Engl J Med. 2012;366:1659-61.

31. WHO and StaR Child Health. Use of standards in paediatric clinical trials in developing countries meeting. Amsterdam 2009 (online). Available from URL: http://www.who.int/child
medicines/progress/Amsterdam_Meeting.pdf. Accessed 2013 Jan 2.

32. Hartling L, Wittmeier KDM, Caldwell P; for the StaR Child Health Group et al. StaR child health: developing evidence-based guidance for the design, conduct, and reporting of pediatric trials. Pediatrics. 2012;129:S112-7.

33. Hartling L, Wittmeier KD, Caldwell PH, et al. StaR Child Health: developing evidence-based guidance for the design, conduct, and reporting of paediatric trials. Clin Pharmacol Ther. 2011;90: 727-31.

34. Caldwell PHY, Dans L, de Vries MC, et al. StaR Child Health: developing evidence-based guidance for the design, conduct, and reporting of paediatric trials. Standard 1: consent and recruitment. Pediatrics. 2012;129:S118-23.

35. Hartling L, Hamm M, Klassen T, et al. StaR Child Health: developing evidence-based guidance for the design, conduct, and reporting of paediatric trials. Standard 2: containing risk of bias. Pediatrics. 2012;129:S124-31.

36. Ellenberg S, Fernandes RM, Saloojee H; for the StaR Child Health Group et al. StaR Child Health: developing evidencebased guidance for the design, conduct, and reporting of paediatric trials. Standard 3: data monitoring committees. Pediatrics. 2012;129:S132-37.

37. van der Tweel I, Askie L, Vandermeer B, et al. StaR Child Health: developing evidence-based guidance for the design, conduct, and reporting of paediatric trials. Standard 4: determining adequate sample sizes. Pediatrics. 2012;129:S138-45.

38. Sinha IP, Altman DG, Beresford MW, et al. StaR Child Health: developing evidence-based guidance for the design, conduct, and reporting of paediatric trials. Standard 5: Selection, measurement, and reporting of outcomes in clinical trials in children. Pediatrics. 2012;129:S146-52.

39. Williams K, Thomson D, Seto I, et al. StaR Child Health: developing evidence-based guidance for the design, conduct, and reporting of paediatric trials. Standard 6: Age groups for pediatric trials. Pediatrics. 2012;129:S153-60.

40. Hoppu K, Anabwani G, Garcia-Bournissen F, et al. The status of paediatric medicines initiatives around the world-what has happened and what has not? Eur J Clin Pharmacol. 2012;68:1-10.

41. Hoppu K, Ranganathan S, Dodoo AN. Realities of paediatric pharmacotherapy in the developing world. Arch Dis Child. 2010;96:764-8.

42. World Health Organization. How to develop and implement a national drug policy. 2003 (online). Available from URL: http://archives.who.int/tbs/ndp/s4869e.pdf. Accessed 2013 Jan 2.

43. World Health Organization. Prequalification programme. A United Nations programme managed by WHO (online). Available from URL: http://apps.who.int/prequal. Accessed 2013 Jan 2.

44. Saint Raymond A. The network of Regulatory Authorities for Paediatric medicines (PmRN). ICDRA pre-conference, Singapore, November-December 2010. Available from URL: http://who. int/medicines/areas/quality_safety/regulation_legislation/WC_1. pdf. Accessed 2013 Jan 2.

45. Pan American Health Organization (online). Available from URL: http://new.paho.org/hq/index.php?option=com_content\&view= article\&id=91\&Itemid=220\&lang=en. Accessed 2013 Jan 7.

46. Mobile Africa 2011. Regional hubs of excellence and innovation. page 42 (online). Available from URL: http://www.mobile monday.net/reports/MobileAfrica_2011.pdf. Accessed 2013 Jan 7.

47. Lester RT, Ritvo P, Mills EJ, et al. Effects of a mobile phone short message service on antiretroviral treatment adherence in Kenya [WelTel Kenya1]: a randomised trial. Lancet. 2010;376: 1838-45. 
48. Levels \& Trends in Child Mortality Report 2011. Estimates developed by the UN Inter-agency Group for Child Mortality Estimation (online). Available from URL: http://www.unicef. org/media/files/Child_Mortality_Report_2011_Final.pdf. Accessed 2013 Jan 7.

49. Black RE, Cousens S, Johnson HL, Child Health Epidemiology Reference Group of WHO and UNICEF, et al. Global, regional, and national causes of child mortality in 2008: a systematic analysis. Lancet. 2010;375:1969-87.

50. Ejemot RI, Ehiri JE, Meremikwu MM et al. Hand washing for preventing diarrhoea. Cochrane Database Syst Rev. 2008;(1): CD004265.

51. Dennehy PH. Effects of vaccine on rotavirus disease in the paediatric population. Curr Opin Pediatr. 2012;24:76-84.

52. Fischer Walker CL, Fontaine O, Young MW, et al. Zinc and low osmolarity oral rehydration salts for diarrhoea: a renewed call to action. Bull World Health Organ. 2009;87:780-6.

53. Bhatnagar S, Wadhwa N, Aneja S, et al. Zinc as adjunct treatment in infants aged between 7 and 120 days with probable serious bacterial infection: a randomised, double-blind, placebo-controlled trial. Lancet. 2012;379:2072-8.

54. Bhutta ZA, Bird SM, Black RE; The Zinc Investigators' Collaborative Group et al. Therapeutic effects of oral zinc in acute and persistent diarrhea in children in developing countries: pooled analysis of randomized controlled trials. Am J Clin Nutr. 2000;72:1516-22.

55. Lazzerini M, Ronfani L. Oral zinc for treating diarrhoea in children (Review). The Cochrane Collaboration 2008 (online). Available from URL: http://www.thecochranelibrary.com/user files/ccoch/file/Water\%20safety/CD005436.pdf. Accessed 2013 Jan 7.

56. Wu T, Ni J, Wei J. Vitamin A for non-measles pneumonia in children. Cochrane Database Syst Rev. 2005(3):CD003700. doi: 10.1002/14651858.CD003700.pub2.

57. Haider BA, Bhutta ZA. Neonatal vitamin A supplementation for the prevention of mortality and morbidity in term neonates in developing countries. Cochrane Database Syst Rev. 2011; (10):CD006980. doi:10.1002/14651858.CD006980.pub2.

58. Lassi ZS, Haider BA, Bhutta ZA. Zinc supplementation for the prevention of pneumonia in children aged 2 months to 59 months. Cochrane Database Syst Rev. 2010; (12): CD005978. doi:10.1002/14651858.CD005978.pub2.

59. Coutsoudis A, Bobat RA, Coovadia HM, et al. The effects of vitamin A supplementation on the morbidity of children born to HIV-infected women. Am J Public Health. 1995;85:1076-81.

60. Mehta S, Fawzi W. Effects of vitamins, including vitamin A, on HIV/AIDS patients. Vitam Horm. 2007;75:355-83.

61. Allen SJ, Okoko B, Martinez E et al. Probiotics for treating acute infectious diarrhoea. Cochrane database Sys Rev. 2010;(11): CD003048. (online). Available from URL: http://www.ncbi. nlm.nih.gov/pubmed/15106189. Accessed 2013 Jan 7.

62. Forsberg BC, Petzold MG, Tomson F, et al. Diarrhoea case management in low and middle income countries - an unfinished agenda. Bull World Health Org. 2007;85:42-8.

63. Blum LS, Oria PA, Olson CK, et al. Examining the use of ORS and other oral rehydration therapy for childhood diarrhoea in Kenya. Am J Trop Med Hyg. 2011;85:1126-33.

64. Christopher JB, Le May A, Lewin S, et al. Thirty years after Alma-Ata: a systematic review of the impact of community health workers delivering curative interventions against malaria, pneumonia and diarrhoea on child mortality and morbidity in sub-Saharan Africa. Hum Res Health. 2011;9:27.

65. Walter ND, Lyimo T, Skarbinski J. Why first-level health workers fail to follow guidelines for managing severe disease in children in the Coast Region, the United Republic of Tanzania. Bull WHO. 2009;87:99-107.
66. Davey P, Brown E, Fenelon L. Interventions to improve antibiotic prescribing practices for hospital inpatients. Cochrane Database Syst Rev. 2005;(4):CD003543.

67. Kredo T, Gerritsen A, van Heerden J, et al. Clinical practice guidelines within the Southern African development community: a descriptive study of the quality of guideline development and concordance with best evidence for five priority diseases. Health Res Policy Syst. 2012; 10:1. doi:10.1186/1478-4505-10-1].

68. Kabra SK, Lodha R Pandey RM. Antibiotics for communityacquired pneumonia in children. Cochrane Database Syst Rev. 2010;(3):CD004874.

69. Report on the global HIV/AIDS epidemic 2002. Joint United Nations Programme on HIV/AIDS; 14th International Conference of AIDS, Barcelona, July 7-12, 2002 (online). Available from URL: https://www.unaids.org/en/media/unaids/contentassets/ dataimport/pub/report/2002/brglobal_aids_report_en_pdf_red_ en.pdf. Accessed 2013 Jan 7.

70. Tarantola D. Current HIV/AIDS trends in the world. National Conference on HIV/AIDS in Botswana. Conference report, August 6-7, 1997 AIDS/STD Unit, Ministry of Health, Gaborone, Botswana.

71. Botswana National AIDS Co-ordinating Agency. Botswana HIV and AIDS Second Medium Term Plan 1997-2002. Ministry of Health, Republic of Botswana (online). Available from URL: http://www.naca.gov.bw/sites/default/files/NSF_final.pdf. Accessed 2013 Jan 7.

72. Weiser S, Wolfe W, Bangsberg D, et al. Barriers to antiretroviral adherence for patients living with HIV infection and AIDS in Botswana. J Acquir Immune Defic Syndr. 2003;34:281-8.

73. USAID HIV/AIDS Health Profile for Botswana, September 2010. (online). Available from URL: http://transition.usaid.gov/our_ work/global_health/aids/Countries/africa/botswana_profile.pdf. Accessed 2013 Jan 7.

74. Tozan Y, Klein EY, Darley S, et al. Prereferral rectal artesunate for treatment of severe childhood malaria: a cost-effectiveness analysis. Lancet. 2010;376:1910-5.

75. Humphreys EH, Nageswaran A, Rutherford GW. Artemisininbased combination therapy for uncomplicated $P$. falciparum malaria in children with HIV (Protocol). Cochrane Database Syst Rev. 2010; (6):CD008556. doi:10.1002/14651858.CD008556.

76. Grimberg BT, Mehlotra RK. Expanding the antimalarial drug arsenal-now, but how? Pharmaceuticals. 2011;4:681-712.

77. Kiszewski AE. Blocking Plasmodium falciparum malaria transmission with drugs: The gametocytocidal and sporontocidal properties of current and prospective antimalarials. Pharmaceuticals. 2011;4:44-68.

78. The RTS,S Clinical Trials Partnership. A phase 3 trial of RTS, S/AS01 malaria vaccine in African infants. New Engl J Med. 2012;367:2284-95.

79. Malaria Vaccine Initiative. PATH, Seattle (online). Available from URL: http://www.malariavaccine.org/latest-news.php. Accessed $2013 \mathrm{Feb} 21$.

80. Hotez PJ, Molyneux DH, Fenwick A, et al. Control of neglected tropical diseases. New Engl J Med. 2008;57:1018-27.

81. Hotez PJ, Fenwick A, Savioli L, et al. Rescuing the bottom billion through control of neglected tropical diseases. Lancet. 2009; 373:1570-5.

82. Madadi P, Enato EFO, Fulga S, et al. Patterns of paediatric analgesic use in Africa: a systematic review. Arch Dis Child. 2012;97:1086-91.

83. Molyneux E. Needless pain in African children: an affront to human dignity. Arch Dis Child. 2012;97:1078-9.

84. Voltaire. La Bégueule. In: Louis Moland (ed) Oeuvres complètes de Voltaire 1772 (Paris, Garnier, 1877-1885), tome 10, page 50. http://www.lib.uchicago.edu/efts/VOLTAIRE/restricted/ VOLTAIRE.bib.html 
85. World Health Organization Make Medicines Child Size initiative (online). Available from URL: http://www.who.int/childmedicines/ en/index.html. Accessed 2013 Feb 23.

86. African Vaccine Regulatory Forum (AVAREF) (online). Available from URL: http://www.who.int/immunization_standards/ vaccine_regulation/africa_network/en/index.html. Accessed 2013 Feb 23.

87. Pan African Clinical Trials Registry (PACTR) (online). Available from URL: http://www.pactr.org/. Accessed 2013 Feb 23.

88. European and Developing Countries Clinical Trials Partnership (EDCTP) (online). Available from URL: http://www.edctp.org/. Accessed 2013 Feb 23.
89. Hill S, Yang A, Bero L. Priority medicines for maternal and child health: A global survey of national essential medicines lists. PloS 2012;7:e38055 (online). Available from URL: http://www. plosone.org/article/info\%3Adoi\%2F10.1371\%2Fjournal.pone.00 38055. Accessed 2013 Jan 2.

90. Yaffe SJ, Aranda JV (eds) Neonatal and paediatric pharmacology: therapeutic principles in practice. 4th ed. Saunders, Philadelphia; 2011.

91. British National Formulary for Children. September 2011-2012. Published by the British Medical Association and Royal Pharmaceutical Society (online). Available from URL: http://www. bnf.org/bnf/index.htm. Accessed 2013 Feb 23. 